\title{
Do amor e da dor: representações sociais sobre o amor e o sofrimento psíquico
}

\author{
From love to pain: social representations about \\ psychological love and suffering
}

\author{
Sheva Maia da NÓBREGA \\ Érica Palmieri Guimarães FONTES ${ }^{2}$ \\ Fabíola Maria Souza Macêdo de PAULA
}

\begin{abstract}
Resumo
Com o objetivo de analisar as experiências afetivas relativas ao amor e ao sofrimento psíquico entre jovens de 18 a 30 anos e adultos entre 31 e 70 anos, com e sem experiência de vida conjugal compartilhada, realizamos a presente pesquisa com uma população de cem sujeitos residentes na cidade do Recife, PE. Utilizamos o multimétodo (qualitativo e quantitativo) e através da Análise Fatorial de Correspondência interpretamos os dados; com relação aos dados qualitativos, foram realizadas análises de acordo com as categorias constituídas. Os resultados, confirmando as hipóteses, revelaram uma diferenciação quanto ao conteúdo representacional conforme as variáveis: grupo etário, inserção social e compartilhamento ou não de vida em comum. A estrutura da representação é similar em todos os grupos. Concluímos que existe uma representação conservadora e metafísica do amor para todos os grupos, destituída de significações ou conotações associadas ao romantismo, sendo que o sofrimento, embora representado por todos os sujeitos como uma experiência de dor e de perda, revela-se diferenciado e determinado pelas variáveis (idade, vida conjugal etc.) dos sujeitos.
\end{abstract}

Palavras-chave: adultos; amor; estados emocionais; intimidade; jovens; sofrimento; representações sociais.

\begin{abstract}
The present research was undertaken in order to analyze young adults and adults' love and suffering experiences. The participants of this paper were 100 people who live in Recife, PE, without conjugal experience distinction. They were considered young adults when their ages were from 18 to 31 years old, and adults for those whose age was from 31 to 70 . The multi-method (qualitative and quantitative) was used, and the data were understood through the Factorial Correspondence Analysis. The qualitative data were analyzed according to the various categories that made up the study. The results, which confirmed the hypothesis, have revealed a representational content differentiation in regards to the variables: age, social position, whether or not there was a conjugal relationship. The structure of the representation was similar in all groups. We conclude there is a conservative and metaphysical representation of love in all groups, devoid of romanticism meanings and connotations. Suffering, although represented by all subjects as an experience of pain and loss, was shown subordinated by the subjects' variables (age, conjugal living, etc.).
\end{abstract}

Key words: adults; love; emotional states; intimacy; young; suffering; social representations.

\section{$\boldsymbol{\nabla} \boldsymbol{\nabla} \boldsymbol{\nabla}$}

1 Departamento de Psicologia, Universidade Federal de Pernambuco. Av. Acad. Hélio Ramos, s/n., CFC480 andar, 50670-901, Recife, PE, Brasil. Correspondência para/Correspondence to: S.M. NOBREGA. Pesquisa realizada com o apoio do PIBIC/CNPq/UFPE. E-mail: <sheva@ufpe.br>.

2 Graduandas, Departamento de Psicologia, Universidade Federal de Pernambuco. Recife, PE, Brasil. Bolsista PIBIC/CNPq/UFPE. 
A presente pesquisa foi realizada com o objetivo de analisar como se manifestam e são representadas, nos dias atuais, experiências relativas às duas maiores dimensões psicoafetivas - o amor e o sofrimento - entre jovens e adultos.

Numerosas classificações sobre os tipos de sentimentos foram construídas no decorrer da História do Conhecimento, tendo se tornado célebres, no século XVII, o "Tratado das Paixões" de Descartes e a "Ética" de Espinosa. São destacadas como fundamentais, no âmbito da psicologia, as díades amor e ódio, alegria e tristeza, além dos sentimentos do eu e de angústia. Embora os estudos em psicologia façam distinção entre sentimentos e emoções, não são enfatizadas, atualmente, as tipologias, mas as investigações das emoções no campo experimental e o desenvolvimento da prática clínica e suas contribuições sobre a dinâmica dos afetos (Maisonneuve, 1966).

Desde a antigüidade, o amor tem sido objeto de interesse dos mais diversos campos de saber, realizando uma travessia histórica desde a mitologia, com o cortejo de deuses e homens em batalha, passando pela literatura, com narrativas de personagens e suas histórias de paixões e tragédias meticulosamente tramadas, especialmente, por Proust e Goethe. O tema, finalmente, conseguiu ser seguramente ancorado na ciência após um longo percurso de mudanças de sentidos.

Platão se interrogou sobre a significação psíquica do amor, no plano fenomenológico e metafísico, encontrando em Eros uma força vital e absoluta. Sua interpretação filosófica desenha a maquete da grande diferença instaurada entre a ética desenvolvida pelo espírito grego e as intenções prescritas pela lei do espírito moderno (Simmel, 1988), estabelecendo a especificidade da ética platoniana em oposição à moderna. Ética, no sentido do filósofo grego, fundada no belo enquanto objeto a ser contemplado, tendo existência e significação universal. Para o grego, a beleza engendra o amor, sendo este último entendido como uma necessidade lógica e, portanto, um servo que tem como objetivo último a contemplação da beleza. Inversamente, a modernidade deposita no amor o mistério e a criatividade autônoma da individualidade, fazendo com que se torne belo o que amamos. "Para nós, a beleza da individualidade e a individualidade da beleza formam uma unidade agindo indissociavelmente, e o que nos separa mais profundamente de Platão é que para ele individualidade e beleza são dissociáveis, o amor operando precisamente a cisão que os separa: ele [o amor] se iguala à beleza e deixa a individualidade fora" (Simmel, 1988, p.197).

No entanto, encontra-se na psicanálise, criada por Freud, o surgimento de uma nova especificidade de conhecimento relativo à temática dos afetos, tendo como finalidade não apenas a explicação dos problemas, mas a finalidade de intervenção em prática clínica sobre a complexidade das dinâmicas afetivas, particularmente, do amor e do sofrimento (Freud, 1910/1969; 1914/1973b). Para Freud (1969; 1914/1973c), todos os sentimentos (de simpatia, amizade, confiança etc.) que experimentamos na vida procedem, em sua gênese, de desejos sexuais na medida em que "primitivamente não conhecemos mais que objetos sexuais" (Freud, 1914/1973a, p.1652), mesmo as pessoas que estimamos e respeitamos na vida cotidiana representam objetos sexuais para nosso psiquismo inconsciente. Ainda no âmbito da psicanálise, Klein (1978) analisa as experiências afetivas de amor e dor como processos constitutivos do eu, tecidos nos mecanismos de projeção e introjeção das relações intersubjetivas desenvolvidas entre os sujeitos.

Enquanto forma particularizada de sentimento, o amor se revela quando uma pessoa deseja e busca de uma outra pessoa receber e dar prazeres ou satisfações, que podem ser de diferentes naturezas, tais como sexuais, de admiração, compreensão, proteção etc. (Doron \& Parot, 1991).

O amor é também o "movimento que conduz um sujeito em direção a outro", uma função imanente constitutiva da vida psíquica, dinâmica conduzida por um objeto, mas não provocado por esse, já que o outro é a representação que o próprio sujeito ocasiona. 0 amor encontra-se, antes de tudo, intrincado no seu objeto e não apenas ligado a ele: o objeto de amor não precede ao amor na sua existência, mas somente tem existência com e pelo amor (Simmel, 1988).

Entendido no sentido mais amplo, o amor pode ser considerado um sentimento que se manifesta na forma de "desejo do outro: o outro sendo um objeto, uma pessoa ou um deus; e o amor no sentido restrito e corrente: atração recíproca dos sexos" (Maisonneuve, 
1966, p.75). Configurado como um fenômeno constituído de dupla face, dor e prazer, o amor encontra-se visceralmente relacionado à dor ou infelicidade quando possuindo existência na ausência de reciprocidade, da mesma forma que representante da felicidade, quando partilhadas e satisfeitas as expectativas dos parceiros.

Segundo o existencialismo de J. P. Sartre, o amor reside na ocorrência simultânea da possessão e do dom, e tudo se passa entre o eu e o outro como uma espécie de troca de bens, em que a possessão do objeto de amor implica tomar o outro como um objeto ou coisa que aliena a liberdade deste último. Um dos amantes dá mais que o outro, o qual recebe e passa a possuir imediatamente mais, de modo que não são duas vidas que trocam uma abundância, mas a existência de uma relação impossibilitada de manter o amor na zona livre do dom (Moscovici, 1988a). A ruptura na possibilidade do equilíbrio permanente de troca evidencia o ser despossuído e acompanhado do mal da solidão. Diante de sua própria nudez, o homem se reconhece incompleto com sua solidão, esvaziado pela presença que o outro preenchia, e que se transformou em condição de sofrimento. Felicidade e sofrimento não existem como correlação lógica, do mesmo modo que o ódio não corresponde ao contrário do amor: é a indiferença que se constitui no contrário do amor (Simmel, 1988b; Doron \& Parot, 1991).

O sofrimento encontra-se na origem da condição humana, uma espécie de vertigem diante da nadificação da condição humana, quando o ser se confronta com a angústia de sua própria finitude, de ser desmunido, inacabado e incompleto. A angústia, portanto, é inerente à condição humana, é uma forma de sofrimento, mas não um estado patológico, já que se trata da relação do homem com sua própria liberdade, ou, como dissera Kierkegaard, a angústia"é a vertigem da liberdade" (Maisonneuve, 1966, p.102).

A palavra sofrimento foi desenvolvida entre os gregos com o termo phérein, que, posteriormente, passou a ser designado sufferre, em latim, significando tolerar, suportar, permitir e, somente no século XVI, entre os franceses assumiu a significação da experiência de uma dor (Barus-Michel, 2001). Entre os planos físico, moral e psíquico, a dor atualmente tem sido também focalizada como uma dimensão da subjetividade, sendo priorizadas as interfaces afetivas e intelectuais.
Durante muito tempo, o sofrimento foi considerado uma experiência dolorosa unicamente experimentada pelos seres humanos, idéia atualmente modificada, sendo reconhecido o sofrimento também entre os animais. O sofrimento consiste numa dor física ou mental prolongada, estado mental experimentado pelo indivíduo, podendo ser avaliado através de critérios objetivos, tais como as condições fisiológicas, o comportamento e o estado geral de saúde (Doron \& Parot, 1991).

Do ponto de vista psicossocial, o sofrimento se situa "no carrefour da subjetividade e da realidade exterior, do individual e do social" (Barus-Michel, 2001, p.122). Ele consiste na expressão de diferentes formas de experiência de mal-estar, tais como: injustiça, humilhação, reificação, rejeição. Todos esses sentimentos encontram-se aglomerados nas condições psicossociais de exclusão e solidão.

O estado de inquietude que a solidão engendra, de sentir-se incompleto, impulsiona o sujeito na busca do outro que, no entanto, é paradoxalmente desejado e temido. Temido porque estranho, misto de necessidade e medo do desconhecido. Mas é precisamente a falta que possibilita a emergência do desejo. Desejo que somente se vincula ao que se furta, se nega, se retrai, se recusa. E no momento em que se realiza um desejo se consome um valor (Moscovici, 1988a).

No que concerne aos processos psicossociais, as representações constituem uma das vias de comunicação do eu com o outro, do sujeito com a realidade que ele constrói e onde se encontra imerso (Berger \& Luckmann, 2000), ou, inversamente, do homem que não está no mundo, mas que sua linguagem é o limite do seu próprio mundo (Wittgenstein, 1992). O ato de se representar a si mesmo consiste num movimento, ao mesmo tempo, reflexivo e de relação com o outro. Considerando que todo objeto de representação, seja ele físico ou social, real ou imaginário, consiste numa relação de desejo do sujeito em relação ao objeto, e que todo desejo encontra-se numa escala de valores, positivos ou negativos, consideramos relevante a análise das representações que os indivíduos podem construir a respeito do amor e do sofrimento.

Particularmente, a teoria das Representações Sociais (RS), elaborada por Moscovici (1976), tem sido 
aplicada à pesquisa no campo da psicologia social (Jodelet, 1989a; 1989b), na investigação sobre as práticas sociais (Abric, 1994) e de exclusão social (Jodelet, 1988b; Abric, 1996). É também utilizada na apreensão de aspectos afetivos/sexuais (Giami, 1983) e de memória social, assim como na explicação de como se articulam elementos socioculturais e de desenvolvimento cognitivo (Doise, 1997) ou simplesmente explorando as ciências cognitivas (Vignaux, 1992).

Uma multiplicidade de pesquisas tem sido desenvolvida em diferentes campos da investigação (Sá, 1998), tanto em âmbito internacional (Abric, 2003) como nacional (Moreira, 2001) nas áreas das ciências sociais, humanas, biomédicas e exatas (Moreira \& Oliveira, 2000), constituindo-se progressivamente como um "paradigma emergente" (De Rosa, 1988a).

Ainda que existam críticas ou divergências relativas à teoria das $\mathrm{RS}$, pode-se observar uma convergência dos pesquisadores que prosseguem aprofundando e desvendando questões inerentes à teoria, inclusive, com proposições teóricas particularizadas (Abric, 1994; Doise \& Mugny, 1997). Entre os que se mantêm na pesquisa e aprofundamento da teoria das RS, todos concordam com o aspecto dinâmico das RS e consideram que elas "se apresentam como uma rede de idéias, metáforas e imagens, mais ou menos interligadas livremente e, por isso, mais móveis e fluidas que teorias [do senso comum]" (Moscovici, 2003, p.210).

Enfatizamos a persistente tarefa de Moscovici (1976; 1988b; 1996) em demonstrar a importância do princípio da indissociabilidade entre indivíduo e sociedade, sujeito e objeto, interno e externo. As formas e os conteúdos das RS revelam-se como uma das provas mais significativas de que as representações coletivas não se constituem um domínio situado à parte, dissociado do psíquico e emocional, como pretendia Durkheim (1912/1985). Nessa perspectiva, realizamos (Nóbrega, 1996; 2003; Nóbrega \& Duarte, 2002) algumas pesquisas sobre diferentes objetos de investigação teórica com o objetivo de analisar os conteúdos e estruturas das representações sociais a partir de redes de associações (Nóbrega, 2003; De Rosa, 1998a; 1998b; 2003), utilizando o teste de associação livre de palavras como técnica projetiva que possibilita a manifestação de conteúdos afetivos latentes e a 80 revelação de estruturas cognitivas.
Considerando que a vivência subjetiva não pode ser compreendida dissociada da inserção social dos sujeitos, realizamos a presente pesquisa sobre as representações que jovens e adultos com e sem experiência de vida conjugal elaboram a respeito do amor e do sofrimento psíquico.

\section{Método}

O momento histórico favorece as ciências sociais e humanas com o desenvolvimento de novas técnicas e metodologias, análises estatísticas mais complexas, como a Análise de Dados (data analysis) nascida há quatro décadas entre os Anglo-Saxões e a Análise Fatorial de Correspondência (AFC), técnica criada na França por J.P. Benzécri nos anos 60 (Cibois, 1990). Adicionam-se proliferações de sofisticados softwares (Abric, 2003) que possibilitam análises de volumosos dados numéricos e/ou verbais processados num tempo cada vez mais curto.

No terreno da psicologia social e das RS, tem sido muito explorada a utilização de multimétodos (quantitativo e qualitativo), assim como a pluralidade de instrumentos mais adequados à obtenção de dados que reflitam mais fielmente as múltiplas facetas dos diferentes objetos. Na presente pesquisa, foram utilizados o método estatístico e o método de análise qualitativa para coleta, processamento e análise dos dados. Com a utilização do teste de associação livre, processado estatisticamente através da Análise Fatorial de Correspondência, verificamos os vínculos existentes entre os diferentes conteúdos representacionais correspondentes às respostas evocadas pelos sujeitos, denominados estatisticamente de variáveis de opinião (Fenelon, 1981; Cibois, 1990; 1991), e variáveis fixas ou sociodemográficas relativas às características de inserção social dos indivíduos (sexo, idade, escolaridade etc.).

Nesta pesquisa, trabalhamos com as seguintes hipóteses:

1. Os diferentes grupos (jovens e adultos) possuem uma estrutura fundamental e semelhante relativa aos objetos representados (amor e sofrimento) na medida em que se encontram implicados em situações de identificação ou de distanciamento em relação aos mesmos; 
2. Inversamente à hipótese anterior, os conteúdos devem variar conforme as diferenças dos sujeitos no que concerne às próprias características (faixa etária, sexo), à experiência (conjugal ou não), e à inserção nos grupos de pertença.

A pesquisa foi realizada na zona metropolitana de Recife, PE, com uma amostra de cem sujeitos de classe social média, sendo incluídos adolescentes, jovens universitários e adultos, com e sem experiência de vida em comum, entre 18 e 70 anos de idade, de ambos os sexos. Classificamos os sujeitos em grupos, conforme experiência afetiva (com prática conjugal e sem experiência de vida compartilhada), e idade (entre 18 e 30 anos, categorizados como grupo de jovens, e entre 31 e 70 anos, entendidos como grupo de adultos).

Foram utilizadas, para coleta de dados, técnicas de natureza projetiva - o teste de associação livre de palavras aplicado à totalidade da amostra ( $n=100)$, e de natureza discursiva (entrevistas em profundidade e semi-estruturadas com 17 sujeitos).

Com o objetivo de apreender conteúdos mais latentes e afetivos com relação aos objetos (amor e sofrimento psíquico), o teste de associação livre tem se revelado apropriado nas pesquisas que investigam a subjetividade dos sujeitos (Nóbrega, 2003; Nóbrega \& Coutinho, 2003). Trata-se de uma técnica semiestruturada, constituída de estímulos indutores verbais ou iconográficos, e que, na presente pesquisa, foi estruturada a partir de quatro estímulos: amor, sofrimento, si mesmo e o outro. Os estímulos nos testes foram colocados em quatro reversíveis ordens de aparecimento para anular o efeito de contágio nas respostas que o estímulo anterior poderia exercer sobre as respostas do estímulo seguinte. A questão colocada, para cada estímulo, consistiu em solicitar aos sujeitos as palavras ou expressões verbais que mais rapidamente Ihe ocorriam à mente quando anunciado o estímulo.

Paralelamente, foram realizadas entrevistas em profundidade com pessoas diferenciadas por sexo e grupo etário. A partir de uma questão padronizada, a entrevista seguia o percurso do pensamento do entrevistado, focalizando e aprofundando os conteúdos evocados relativos aos objetos de representação (amor, sofrimento, o outro e si mesmo). Em seguida, foram aplicadas entrevistas semi-estruturadas com outros sujeitos, sendo abordadas questões que se destacaram anteriormente nas entrevistas em profundidade. $\mathrm{O}$ número foi determinado pelo critério de saturação (Sá, 1992), sendo concluídas em um total de 17 entrevistas.

As entrevistas foram agrupadas conforme os critérios de classificação dos grupos; as categorias foram analisadas e organizadas (Bardin, 1989) de acordo com o aparecimento de temas relativos aos conteúdos que se referiam aos objetos-estímulos, com cada tema agrupando categorias e subcategorias, em forma de árvore.

Quanto ao teste de associação livre, inicialmente, foram organizados quatro dicionários correspondentes a cada estímulo indutor contendo todas as palavras evocadas por todos os sujeitos indistintamente. Foram processadas no Tri-Deux Mots ${ }^{3}$ um total de 1437 palavras; após o agrupamento por similaridade semântica, foram computadas 733 palavras diferentes. Finalmente foi elaborado o banco de dados e, em seguida, realizada a AFC. Para a configuração do gráfico resultante do processamento estatístico, foram consideradas apenas as palavras com freqüência de repetição mínima e acima de dez vezes.

\section{Resultados}

A análise do plano fatorial é feita a partir do jogo de oposições reveladas pelas modalidades (respostas aos estímulos indutores) a partir dos resultados da AFC. Para Comby et al. (1993, p.11), "o princípio da AFC consiste em colocar em destaque a estrutura dos desvios à independência destacando os eixos e, com esse procedimento, explicando uma maior ou menor parte da variância total das respostas". A AFC permite mostrar uma estrutura mais central em relação a outros elementos do campo representacional e, portanto, a expressão da organização cognitiva a respeito de um objeto representado. Desse modo, torna-se evidenciado que "os sujeitos não partilham (ou não unicamente) um referente categorial comum mas

3 Tri-Deux Mots - Versão 2.2 de 2000, elaborado por Philippe Cibois (1990; 1991). 
(igualmente) as funções de tratamento da informação implicando diferentes critérios de recortes ou decodificações, de organização e de orientação dos elementos do campo" (Doise et al., 1992, p.56).

Tornou-se convenção na literatura estatística sobre AFC (Fenelon, 1981; Cibois, 1990) que o eixo 1, ou fator 1, ocupe a posição horizontal no gráfico e que o fator 2 se mantenha na vertical. No que concerne à presente pesquisa, detivemo-nos sobre a análise dos dois primeiros fatores que revelaram os seguintes resultados: o fator 1 explica 92,6\% da variância total de respostas (valor próprio = 0.184), e o fator 2 explica 7,2\% de variância (valor próprio=0.014), perfazendo um total de 99,8\% da variância total.

A representação gráfica dos planos fatoriais 1 e 2 (F1 e F2) (Figura 1), a seguir, revela com clareza como se estrutura a RS sobre o amor e o sofrimento. O mapa fatorial é determinado pelas respostas aos quatro estímulos indutores que mais contribuíram à formação dos eixos. As palavras respostas são representações ou, na linguagem estatística, modalidade de opinião. Elas contribuem na construção dos eixos ou fatores 1 e 2 que configuram o plano fatorial. Quando a palavra aparece acompanhada de um número, significa que aquela resposta ou modalidade de opinião contribuiu para a construção de um dos eixos ou dos dois eixos, simultaneamente, conforme os valores evidenciados na AFC.

Pode-se observar nessa distribuição que somente a variável fixa, faixa etária, demonstrou relevância na composição do espaço gráfico, e que o grupo de jovens se encontra em oposição às representações construídas pelo grupo de adultos, com relação ao amor e ao sofrimento. Após cada palavra e colado à mesma, encontra-se um número correspondente ao estímulo indutor das respectivas respostas, conforme explicita a legenda abaixo do gráfico, sobre as variações dos quatro estímulos.

Pode-se observar que todas as representações do amor são avaliadas de modo positivo, independen-

doença2 F2

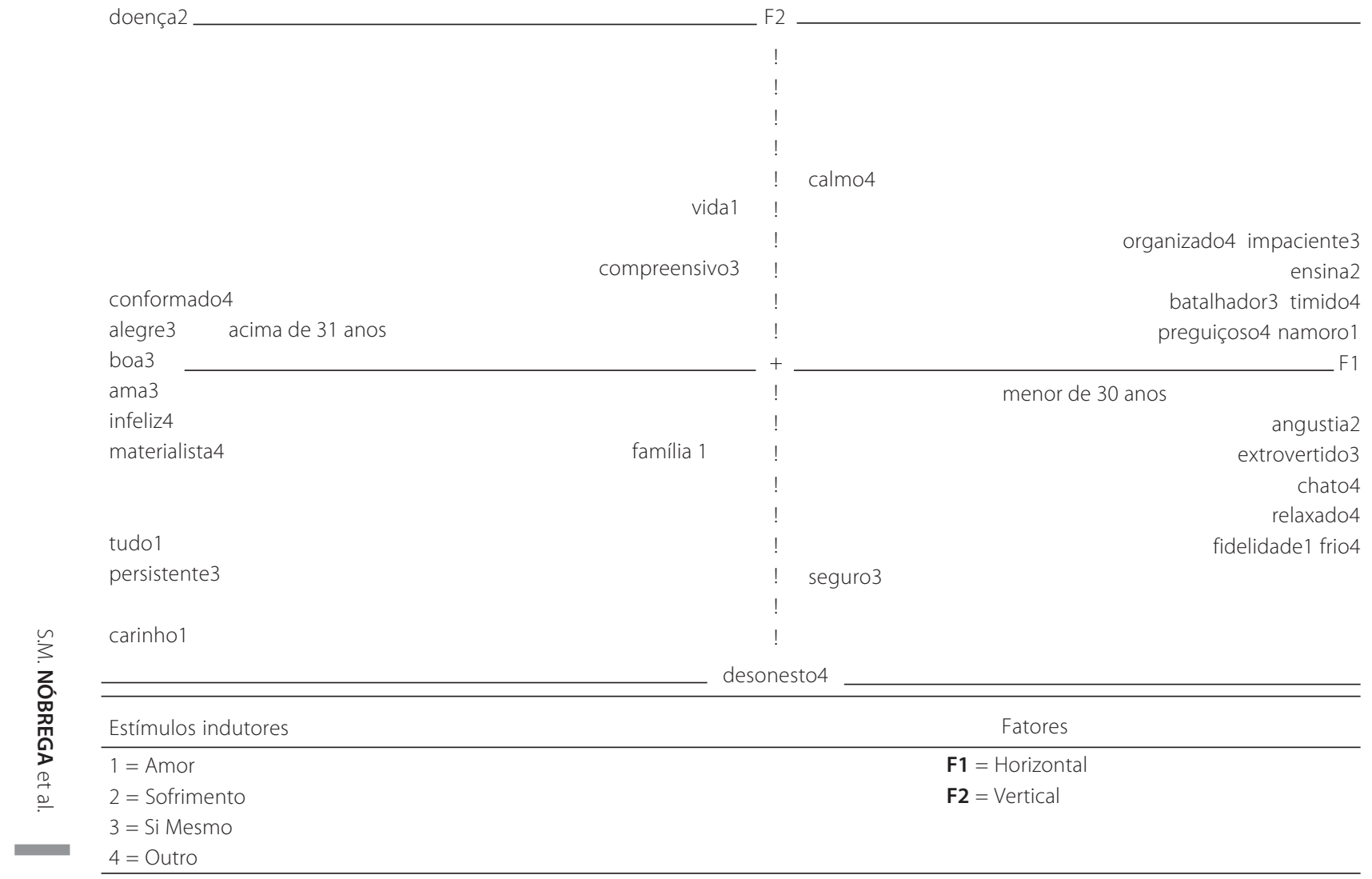

82 Figura 1. Representação gráfica do plano fatorial. 
temente da faixa etária, sexo, compartilhamento ou não de experiências com parceiro(a)s. Trata-se da primeira hipótese relativa à semelhança na estrutura do campo representacional, da relação existente entre o sujeito e o objeto da representação.

O eixo 1 (F1), horizontal, indica as representações que mais contribuíram na constituição desse fator. Podemos encontrar diferenças nas respostas quanto ao conteúdo da RS do amor. Para o grupo de jovens, o amor aparece (F1, lado positivo, à direita) como namoro $(C P F=21)^{4}$ e fidelidade (CPF=29). Posicionando-se em oposição a esse grupo, no mesmo eixo fatorial (F1, lado negativo, à esquerda), encontra-se o grupo de adultos com experiência afetiva compartilhada, que qualifica o amor de carinho (CPF=51), mas que tem a significação de que é tudo (CPF=51). Ainda nesse eixo, surgem as representações relativas ao sofrimento que, para os jovens, significa angústia ( $C P F=41)$, mesmo sendo atribuída a existência de uma aprendizagem com a experiência do sofrimento, na medida em que ele ensina (CPF=28). Para os sujeitos do grupo de adultos, a única evocação sobre o sofrimento é simbolizada na doença (CPF=53).

A representação de si mesmo é adjetivada de forma predominantemente positiva (Tabela 1), ainda que se destaquem alguns aspectos negativos. O jovem se percebe (F1, lado positivo) como batalhador ( $C P F=33)$, extrovertido (CPF=36), embora impaciente (CPF=33). Para esse grupo, o outro é representado como preguiçoso $(C P F=46)$, frio $(C P F=29)$, chato $(C P F=24)$ e tímido ( $C P F=24)$. Os adultos (F1, lado negativo) consideram-se alegres ( $C P F=47)$, persistentes $(C P F=56)$, pessoas boas ( $C P F=52)$ e que amam ( $C P F=47)$. O outro é mantido à distância e com reservas porque é considerado materialista (CPF=51), infeliz $(C P F=61)$ e conformista (CPF=56). A tabela abaixo expressa as contribuições de cada modalidade na construção dos fatores.

Tabela 1. Representações com freqüência igual e acima de 5\%.

\begin{tabular}{|c|c|c|c|c|c|c|c|}
\hline Amor & $\%$ & Sofrimento & $\%$ & Si mesmo & $\%$ & Outro & $\%$ \\
\hline Família & 45,0 & Dor & 44,0 & Amigo & 34,0 & Desleixado & 27,0 \\
\hline Vida & 38,0 & Ruim & 34,0 & Compreensivo & 32,0 & Falso & 21,0 \\
\hline Felicidade & 34,0 & Morte & 33,0 & Feliz & 27,0 & Egoísta & 21,0 \\
\hline Amizade & 32,0 & Perda & 31,0 & Responsável & 24,0 & Chato & 19,0 \\
\hline Deus & 32,0 & Tristeza & 26,0 & Sincero & 23,0 & Organizado & 19,0 \\
\hline União & 27,0 & Ensina & 22,0 & Complicado & 22,0 & Nervoso & 18,0 \\
\hline Cumplicidade & 22,0 & Solidão & 18,0 & Calmo & 21,0 & Extrovertido & 15,0 \\
\hline Compreensão & 15,0 & Angústia & 17,0 & Seguro & 16,0 & Desonesto & 14,0 \\
\hline Complexo & 13,0 & Doença & 11,0 & Extrovertido & 15,0 & Calmo & 14,0 \\
\hline Namoro & 12,0 & Rejeição & 9,0 & Tímido & 15,0 & Infeliz & 13,0 \\
\hline Carinho & 11,0 & Depressão & 9,0 & Batalhador & 14,0 & Frio & 12,0 \\
\hline Fidelidade & 11,0 & Separação & 8,0 & Inteligente & 14,0 & Conformado & 12,0 \\
\hline Tudo & 11,0 & Decepção & 8,0 & Impaciente & 14,0 & Materialista & 11,0 \\
\hline Paz & 9,0 & Falta & 8,0 & Vaidoso & 13,0 & Preguiçoso & 10,0 \\
\hline Dedicação & 9,0 & Frustração & 7,0 & Persistente & 12,0 & Tímido & 10,0 \\
\hline \multirow[t]{10}{*}{ Sexo } & 9,0 & Preocupação & 7,0 & Bom & 12,0 & Incompreensivo & 9,0 \\
\hline & & Incompreensão & 7,0 & Alegre & 10,0 & Irresponsável & 8,0 \\
\hline & & Traição & 5,0 & Ama & 10,0 & Confiante & 8,0 \\
\hline & & & & Impulsivo & 9,0 & Impaciente & 6,0 \\
\hline & & & & Legal & 9,0 & Indeciso & 6,0 \\
\hline & & & & Trabalha & 7,0 & & \\
\hline & & & & Carinhoso & 7,0 & & \\
\hline & & & & Dominador & 6,0 & & \\
\hline & & & & Dinâmico & 5,0 & & \\
\hline & & & & Inseguro & 5,0 & & \\
\hline
\end{tabular}

$\boldsymbol{\nabla} \mathbf{v} \boldsymbol{\nabla}$

4 Indicação das coordenadas fatoriais e o valor correspondente a cada modalidade ou representação na construção dos fatores (CPF= contribution par facteur). 
No que concerne ao eixo 2 (F2), vertical, tornam-se evidenciadas as representações entre os adultos e jovens com relação ao amor como expressão da vida $(C P F=126)$, sendo que para os jovens com experiência conjugal fica configurada a representação da família (CPF=26), enquanto os jovens sem experiência de vida conjugal evidenciam a importância da fidelidade $(C P F=21)$. Ainda a doença se repete como representação de sofrimento para os adultos, no eixo 2 assim como no eixo 1, sendo que com os jovens não ocorreu nenhuma evocação relativa ao sofrimento no eixo 2 . Ainda no eixo 2, o grupo de adultos considera-se compreensivo $(C P F=25)$, enquanto os jovens se representam como impacientes (F1, CPF=33; F2,CPF=27), e também seguros de si (CPF=46). Para os jovens com e sem experiência de vida conjugal, o outro é representado como desonesto $(C P F=104)$, relaxado ( $F 1, C P F=44 ; F 2, C P F=33)$ e frio (F1, CPF=29; $F 2, C P F=31)$. Os adultos ponderam na percepção do outro, considerando-o calmo $(C P F=54)$ e organizado (CPF=37).

Com relação à segunda hipótese, de que existem diferenças significativas no que concerne aos conteúdos representacionais de cada grupo, fica evidenciada, também, a confirmação dessa hipótese quanto à idade. Quando comparamos as respostas dos jovens às dos adultos, fica evidenciado que os mais jovens se consideram aprendizes dos afetos na medida em que representam o sofrimento não apenas como produtor do que há de negativo, como a angústia, mas enfatizam os resultados positivos de crescimento pessoal, obtidos através da aprendizagem com as experiências dolorosas, revelada na expressão: "a dor também ensina". Os mesmos evocam adjetivos referentes às expectativas de construção de vida afetiva, traduzindo o amor como fidelidade testada na fase de namoro. Os adultos encontram no amor uma forma totalizadora e genérica de vida em comum (o amor é tudo), mas também uma forma de carinho. A tabela a seguir demonstra a diversidade de respostas evocadas pela totalidade dos sujeitos. Encontram-se aqui demonstradas as representações que tiveram repetição com freqüência igual e superior a 5\%, considerando que, do ponto de vista da análise de conteúdo, a variedade semântica é importante para explicação da totalidade dos dados coletados, embora estatistica- mente, na configuração do gráfico, tenham sido consideradas as respostas com freqüência superior a $10 \%$.

É interessante observar alguns dados no que se refere à relação estabelecida entre o eu e o outro, particularmente com relação ao processo de comparação social (Tabela 1). Os entrevistados se representam como possuidores de atributos de conotação positiva, mas quando se comparam ao outro, os qualificativos transformam-se no verso da figura humana. Os sujeitos entrevistados consideram-se amigos, compreensivos, felizes, responsáveis, sinceros etc., com efeito, enfatizando o aspecto da sociabilidade. Curiosamente, a afetividade como Eros ou vida pulsional é esvaziada pela frágil e solitária evocação da resposta de que ele ama. O outro é considerado egoísta, desleixado, incompreensivo, conformado e nervoso, para os sujeitos com vida conjugal, enquanto os jovens sem experiência de vida compartilhada identificam o outro como falso, chato, impaciente, desonesto, irresponsável etc. Existe aqui uma diferença cognitiva e afetiva quanto à variável faixa etária, evidenciada na qualidade das conotações dos adjetivos evocados na medida em que as pessoas com experiência de vida conjugal são mais reivindicativas no compartilhamento e reciprocidade de trocas quando evocam respostas como"egoísta, incompreensivo" endereçadas ao outro, supostamente parceiro. Como analisamos acima, a relação amorosa experimentada como possessão reifica e aliena a liberdade do objeto de amor, tendo por efeito a impossibilidade de manter o amor na zona livre do dom.

De modo geral, o amor é representado, do ponto de vista cognitivo, com conotações conservadoras (ancoragem) construídas sobre dois pilotis (família e vida) com funções distintas, mas que se encerram em um mesmo sentido. De um lado, no que concerne aos valores conservadores da sociedade, pois quase metade da população interrogada, jovens e adultos, representa a família (45\%) como expressão do amor. Por outro lado, no sentido pulsional de conservação ou preservação da espécie, o amor é vida (38\%). No que se refere ao fator erótico da sensualidade afetiva, existe unicamente uma frágil evocação do sexo (9\%), representada particularmente pelos jovens com e sem experiência de vida compartilhada (52\%). É curioso que, 
apenas com esse grupo, a representação do amor encontra-se vinculada incondicionalmente ao imperativo da presença material do objeto. Através das entrevistas, a objetivação das representações encontra-se materializada, por um lado, como energia pulsional revelada nas respostas de: "impulso, vontade plena, intensidade, pegar, tocar, abraço, beijo, olhar, paixão, amor sexual, atração sexual"; e, por outro lado, como desejo fusional com o objeto: "completar-se, convívio, compartilhar, fazer as coisas juntos". Existe, também, a representação mais genérica da vida como combustível que abastece e renova os laços de sociabilidade (Moscovici, 1988a) na dinâmica psicossocial dos sujeitos através da união, representação mais presente (27\%) entre os jovens com experiência de vida compartilhada.

A felicidade (34\%) é idealizada, e o amor vem acompanhado de conteúdo metafísico quando associado a Deus (34\%), qualificando, desse modo, o amor como esfera impalpável, longínqua aos mortais. Amor é também uma forma de amizade (32\%), expressão de afeto que não é dirigido ao outro enquanto outro, objeto de amor, mas com relação ao próprio sujeito na medida em que é suscitado pela atração que a semelhança do outro a um modelo ideal exerce sobre si mesmo (Maisonneuve, 1966). Observamos, portanto, uma concepção metafísica do amor, desprovida de significação fundada na predominância do Eros.

No paradoxo da experiência amorosa, o sofrimento surge como inevitável. Diferentemente do amor, que não revela uma representação unitária para todos os sujeitos, o sofrimento reúne todos os interrogados em torno de uma mesma representação. Os elementos figurativos (Moscovici, 1976), ou do núcleo central (Abric, 1994), constituintes da RS, são a dor e a perda para toda a população interrogada, independentemente das variáveis idade e compartilhamento ou não de vida em comum.

O sofrimento torna-se particularizado no que conceitualmente é denominado de elementos periféricos que, magnetizados, giram em torno dos elementos figurativos em função das variáveis que distinguem os grupos. Dissolvida entre os diferentes grupos, dos mais jovens aos adultos, destaca-se a representação da morte. Entre os adultos de idade mais avançada, esse conteúdo mistura-se com a presença da doença. Lembramos que esse grupo atinge a idade de 70 anos, geração mais preocupada com a questão da saúde (vida versus morte), representação predominantemente constituída de conteúdos referentes ao aspecto físico-corporal.

Colocando-se em posições antagônicas às RS dos adultos, os jovens localizam o sofrimento unicamente no âmbito dos afetos, particularmente os que concernem às experiências de descontentamento. Os jovens que não tiveram vida compartilhada com parceiro(a) associam a dor à experiência de rejeição, traição, solidão. A representação de que o sofrimento ensina é paradoxalmente adicionada ao amargo coquetel de elementos que constituem os afetos negativos. Provavelmente, encontra-se nesse paradoxo do sofrimento, como produtor de aniquilamento e constituição do eu, a fundamental porção da magia do amor. Certamente o elemento amor se constitui combustível mobilizador do jovem, na incessante busca do objeto de desejo, mantendo-o incansavelmente num contínuo processo de aprendizagem.

Ainda confirmando a hipótese 1, no que concerne à estrutura, os grupos não se diferenciam uma vez que todos os sujeitos interpretam a realidade como dimensões bipolarizadas, seja na interpretação do amor versus sofrimento, seja como saúde versus doença (Herzlich, 1969). Os elementos representacionais são selecionados de modo hierarquizado na forma de categorias organizadas em pólos oposicionistas, nos quais os aspectos caracterizados como positivos são identificados ao amor (felicidade, amizade, vida), assim como as representações elaboradas sobre si mesmo (amigo, compreensivo, feliz). Em pólo oposto, as atribuições predominantemente negativas referem-se ao outro, ficando estabelecido o distanciamento social realizado através do mecanismo de comparação social com relação ao que é considerada a alteridade (egoísta, nervoso, desonesto, falso etc.), caracterizada na visão dicotômica de interpretação da realidade.

\section{Conclusão}

A pesquisa coloca em evidência a dialética que se instaura entre os sistemas cognitivo e social dos indivíduos, destacando as diferenças de conteúdos 
representacionais já que os sujeitos partilham socialmente as RS quanto às suas funções (orientação na comunicação, edificação de condutas, identitária e justificadora) ainda que de modo diferenciado, o que implica critérios particularizados no tratamento das informações absorvidas e na construção seletiva das representações dos respectivos grupos.

É importante destacar que o amor pulsional, no sentido filosófico de Simmel (1988b), assim como psicanalítico (Freud, 1914/1973b), é totalmente indiferente a uma relação finalizada, excluindo qualquer interesse em colocar-se como um meio a serviço da reprodução da espécie. A natureza erótica do amor ignora os elevados níveis de natureza ética, colocando-se acima dos vínculos finalizados e impedindo de colocar sua existência a serviço da vida ou da procriação. O ser que ama encontra-se liberado de toda relação finalizada, sendo que o hedonismo, o egoísmo ou a relação moralista e altruísta não se constituem senão formas de vincular-se ao seu estado, que é "simplesmente um ser e não um agir" (Simmel, 1988b, p.175).

Se considerarmos a perspectiva teórica de que a constituição do sujeito se encontra inevitavelmente articulada à existência do objeto (o outro), através do qual se torna possível o reconhecimento de si mesmo e da diferença que o outro representa, a dor e a perda traduzem a simultaneidade do ato indissociável de constituição sujeito-objeto. Na publicação Si j'était vous..., Klein (1978) introduz o conceito de"identificação projetiva" para explicar a gênese de processos defensivos que o indivíduo, numa idade muito precoce, precisamente no decorrer dos quatro primeiros meses de vida, desenvolve: mecanismos projetivos como forma de reintegração do ego. A partir desse período, a relação da criança com seu objeto de amor se modifica em função do seu reconhecimento como distinto do outro (antes apreendido como objeto total), determi$\varkappa$ nando a separação sujeito-objeto e, simultaneamente, z. ressentindo a falta do objeto amado. A dor provocada 䝆 com o distanciamento do objeto, e vivenciada como ᄀ uma perda, torna possível a constituição do sujeito e o

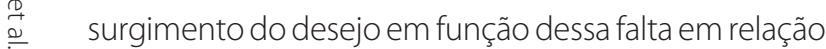
ao objeto. Evocada por 44\% da população no teste de associação livre, embora presente na quase totalidade

86 das entrevistas, a dor é revelada como uma ação psíquica compartilhada com a representação de perda e falta.

Embora algumas expressões de amor e de dor façam eco à memória social das mesmas fórmulas, interrogamo-nos se os sujeitos que escutamos estariam nos comunicando o desinvestimento das relações amorosas, nos modelos tradicionalmente conhecidos, e substituindo-as por "vivências de experiências" ou, quem sabe, informando-nos sobre o que é possível ser feito do amor nos tempos de hoje.

\section{Referências}

Abric, J-C. (Dir.) (1994). Pratiques Sociales et représentations. Paris: PUF.

Abric, J-C. (Dir.) (1996). Exclusion sociale, insertion et prévention. Saint-Agne: Editions Erès.

Abric, J-C. (Dir.) (2003). Méthodes d'études des représentations sociales. Ramonville Saint-Agne: Éditions ères.

Bardin, L. (1989). L'analyse de contenu (5a ed.). Paris: PUF.

Barus-Michel, J. (2001). Souffrance, trajets, recours. Dimensions psycosociales de la souffrance humaine. Bulletin de Psychologie, 54 (2), 122.

Berger, P.L., \& Luckmann, T. (2000). A construção social da realidade (19a ed., p.175). Petrópolis: Vozes.

Cibois, P. (1990). L'analyse des données en sociologie (2th ed.). Paris: PUF.

Cibois, P. (1991). L'analyse factorielle (3th ed.). Collections Qui sais-je? Paris: PUF.

Comby, L., Devos, T.H., \& Deschamps, J-C. (1993). Représentations sociales du sida et attitudes l'égard des personnes séropositives. Les Cahiers Internationaux de Psychologie Sociale, (17), 11.

De Rosa, A.S. (2003). Le "réseau d'associations": Une technique pour détecter la structure, les contenus, les indices de polarité, de neutralité et de stéréotypie du champ sémantique liés aux représentations sociales, In J-C. Abric. Méthodes d'études des representations sociales (pp. 81-117). Ramonville Saint-Agne: Éditions ères.

De Rosa, A.S. (1988a). Struttura e contenuti della reppresentazione sociale del "malato mentale" in bambini, genitori ed insegnanti. Rassegna di psicologia (v1, pp. 2-53). Roma: Bulzoni.

De Rosa, A.S. (1988b). Sur l'usage des associations libres dans l'étude des représentations sociales de la maladie mentale. Connexions, 51, 27-50.

Doise, W., \& Clémence, A., \& Lorenzi-Cioldi, F. (1992). Représentations sociales et analyses de données (p. 56). Paris: Presses Universitaires de Grenoble.

Doise, W., \& Mugny, G. (1997). Psychologie sociale \& développement cognitif. Paris: Armand Colin. 
Doron, R., \& Parot, F. (1991). Dictionnaire de Psychologie. Paris: PUF.

Durkeim, É. (1912/1985). Les formes élémentaires de la vie religieuse (7a ed.). 1985. Paris: PUF.

Fenelon, J-P. (1981). Qu'est-ce que l'analyse des données? Paris: Lefonen.

Freud, S. (1910/1969). Contribuições para a Psicologia do amor. Rio de Janeiro: Imago.

Freud, S. (1914/1973a). La dinamica de la transferencia. In S. Freud. Obras completas (3a ed., Tomo II, p.1652). Madrid: Biblioteca Nueva.

Freud, S. (1914/1973b). Duelo y melancolia. In S. Freud. Obras completas (3a ed., Tomo II). Madrid: Biblioteca Nueva.

Freud, S. (1914/1973c). Observaciones sobre el "amor de transferencia". In Obras completas (3a ed., Tomo II), Madrid: Biblioteca Nueva.

Giami, A., Hubert-Viveret, C., \& Laval, D. (1983). L'ange et la bête: représentation de la sexualité des handicapés mentaux par les parents et les éducateurs. Paris: PUF, CTNERHI.

Herzlich, C. (1969). Santé et Maladie: Analyse d'une représentation sociale. Paris: EHESS.

Jodelet, D. (1989a). Les représentations sociales. Paris: PUF

Jodelet, D. (1989b). Folies et représentations sociales. Paris: PUF.

Klein, M. (1978). "Si j'était vous...". In B. Grunberger, \& J. Chasseguet-Smirgel. L'indentification: l'autre c'est moi. Paris: Tchou éditeur.

Maisonneuve, J. (1966). Psycho-sociologie des affinités (pp.75-102). Paris: PUF.

Moscovici, S. (1976). La psychanalyse, son image et son public (2a ed.). Paris: PUF.

Moscovici, S. (1988a). La machine à faire des dieux. Paris: Fayard.

Moscovici, S. (1988b). Notes towards a description of social representations. European Journal of Social Psychology, 18.
Moscovici, S. (1996). Communications et représentations sociales paradoxales. In J-C. ABRIC. Exclusion sociale, insertion et prévention. Saint-Agne: Editions Erès.

Moscovici, S. (2003). Representações Sociais: investigações em psicologia social (p.210). Petrópolis: Vozes.

Moreira, A.S.P. (2001). Representações Sociais: teoria e prática. João Pessoa: Editora Universitária UFPB.

Moreira, A.S.P., \& Oliveira, D.C. (2000). Estudos Interdisciplinares de Representação Social (2a ed.). Goiânia: $A B$.

Nobrega, S.M. (2003). Représentations sociales de la folie par les familles de malades mentaux au nord-est du Brésil; le cas João Pessoa. Paris: Éditions du Septentrion.

Nobrega, S.M. (1996). Repésentation Sociale de la folie: la construction de l'altérité sur la figure du ou. In Deuxième Conférence Internationale sur les Représentations Sociales. Aix-en-Provence.

Nóbrega, S.M., \& Coutinho, M.P.L (2003). O teste de associação livre de palavras. In M.P.L. Coutinho, A.S. Lima, F.B. Oliveira \& M.L. Fortunato. Representações Sociais: uma abordagem interdisciplinar (pp.67-77). João Pessoa: Editora Universitária UFPB.

Nóbrega, S.M., \& Duarte, M.L. (2002). Solitude: (des)construction du sujet? In Quatrième Conférence Internationale sur les Représentations Sociales. Montreal, Canadá.

Sá, C.P. (1998). Sobre a construção do objeto de pesquisa em representações sociais. Rio de Janeiro: UERJ.

Simmel, G. (1988a). Fragment sur l'amour (écrits postumes). In Philosophie de l'amour. Paris: Editions Rivages.

Simmel, G. (1988b). Philosophie de l'amour (p. 175). Paris: Editions Rivages.

Vignaux, G. (1992). Les sciences cognitives: une introduction. Paris: Éditions La Découverte.

Wittgenstein, L. (1992). Tratactus logico-philosophicus. Paris: Gallimard.

Recebido para publicação em 25 de setembro de 2003 e aceito em 19 de outubro de 2004. 
